\title{
TENSÕES ENTRE DISCURSOS: CRUZAMENTO DE FRONTEIRAS ENTRE OS DISCURSOS CIENTÍFICO E COTIDIANO NA FORMAÇÃO INTERCULTURAL DE PROFESSORES DE CIÊNCIAS PARA O CAMPO
}

\author{
TENSIONS BETWEEN SPEECHES: BORDER CROSSING BETWEEN THE SPEECHES \\ IN SCIENTIFIC AND EVERYDAY INTERCULTURAL TRAINING OF RURAL \\ SCIENCE TEACHERS
}

\author{
Tânia Halley Oliveira Pinto ${ }^{1}$ \\ Maria Emília Caixeta de Castro Lima ${ }^{2}$ \\ Andréa Horta Machado ${ }^{3}$
}

\begin{abstract}
Resumo: Neste artigo, resultado de uma pesquisa realizada na Licenciatura em Educação do Campo da Universidade Federal de Minas Gerais (UFMG), propomo-nos refletir sobre como licenciandos do campo se apropriaram da cultura científica e mediaram o encontro/confronto de pontos de vista entre o discurso científico e o discurso do cotidiano dos educandos. Analisamos na perspectiva da Análise Textual Discursiva atividades construídas no contexto de uma sequência intercultural. Conforme a ressignificação do discurso científico, deparamonos com ideias bem demarcados dos educandos pela não colonização do discurso pessoal pelo discurso científico. Seus discursos fortemente demarcados pela não colonização de seus discursos nos indica que esses sujeitos colocam em jogo suas existências como sujeitos ativos de aprendizagem, capazes de inter-relacionar o conhecimento forjado em suas experiências de humanidades, em seus territórios, povoados por seus passados, memórias e ancestralidades como culturas válidas, como também produção de conhecimento.
\end{abstract}

Palavras-chave: Educação do Campo; ensino de ciências intercultural; apropriação de discurso.

\begin{abstract}
In this paper, the result of a research carried out in the Undergraduate course in Rural Education of the Federal University of Minas Gerais (UFMG), we propose to reflect on how graduates of the field appropriated scientific culture and mediated the meeting/confrontation of points of view between scientific discourse and the discourse of the daily life of students. We analyze from the perspective of Discursive Textual Analysis activities built in the context of an intercultural sequence. According to the resignification of scientific discourse, we are demarked with ideas of the students by the non-colonization of personal discourse by scientific discourse. His discourses strongly demarcated by the non-colonization of their discourses indicate that these subjects put at stake their existences as active subjects of learning, capable of interrelating the knowledge forged in their experiences of humanities, in their territories, populated by their pasts, memories and ancestry as valid cultures, as well as production of knowledge.
\end{abstract}

Keywords: Rural Education; intercultural science teaching; speech appropriation.

\section{Introdução}

Numa sociedade hierarquizada e desigual, pautada pela noção meritocrática de acesso a bens e direitos, acompanhamos há algumas décadas a luta de coletivos de sujeitos por bens

\footnotetext{
${ }^{1}$ Universidade Federal do Triângulo Mineiro, Uberaba, MG, Brasil.

${ }^{2}$ Universidade Federal de Minas Gerais, Belo Horizonte, MG. Brasil.

${ }^{3}$ Universidade Federal de Minas Gerais, Belo Horizonte, MG. Brasil.
} 
culturais e materiais que historicamente lhes foram negados. Dentre as pautas e bandeiras levantadas por esses sujeitos encontramos, na luta pela reforma agrária, uma incorporação de tantas outras lutas em seu bojo, como o direito à terra, território, saúde, reconhecimento de suas identidades culturais e o direito à educação (ARROYO, 2014). Entrelaçados, esses direitos básicos universais, dão forma e corpo às políticas públicas de Educação do Campo que visam garantir o acesso à educação, bem como a permanência dos sujeitos do campo nas instituições de ensino, sejam elas da educação básica ou de nível superior (ANTUNES-ROCHA, 2009).

A abertura de licenciaturas específicas para formação de professores do campo é ainda recente no cenário nacional (ARROYO, 2008; 2013), movimento iniciado em 2005 é fruto da demanda por expansão e garantia de uma formação de professores mais adequada à realidade do campo brasileiro, que pense na concepção da escola do campo, da aprendizagem do campesinato e da formação de educadores no/do/para o campo (ANTUNES-ROCHA, 2009; PIO-VENÂNCIO, 2011). Desse contexto de criação e institucionalização das Licenciaturas em Educação do Campo nas universidades é que surge a parceria entre a Faculdade de Educação da Universidade Federal de Minas Gerais (UFMG) e o Movimento dos Trabalhadores Rurais Sem Terra (MST) com apoio do Programa Nacional de Educação na Reforma Agrária (PRONERA), resultando inicialmente na gênese do curso de Pedagogia da Terra (PeTerra) na UFMG, em 2005, que se consolida na Licenciatura em Educação do Campo (LECampo), em 2008, prevendo a oferta anual de uma das área de conhecimento: Ciências da Vida e da Natureza, Linguagens, Ciências Sociais e Matemática (a cada ano é oferecida a entrada em uma das habilitações).

Assim, é do cerne do processo de formação de sujeitos do campo que cursavam o sexto período da LECampo/UFMG, habilitação Ciências da Vida e da Natureza (CVN) que partimos com o objetivo de analisar a apropriação realizada por licenciandos do campo acerca dos conceitos de evolução e diversidade biológica, registrada em atividades durante uma disciplina organizada numa perspectiva de educação intercultural em ciências. Nos propomos a refletir sobre como os licenciandos do campo se apropriaram da cultura científica e mediaram esse modo de ver o mundo no encontro/confronto de pontos de vista com aqueles que fazem parte de seus universos culturais de explicação do mundo, ou seja, como estes licenciandos têm aprendido a pôr em relação culturas ou visões de mundo diferentes.

Nas seções a seguir discutiremos que formação de professores de ciências para o campo defendemos e em qual perspectiva de formação intercultural de ciências nos apoiamos. Explicitaremos as condições de produção e análise dos dados da pesquisa realizada. E por fim, tecemos apontamentos a partir das lições aprendidas com os sujeitos do campo.

\section{De que formação de professores de ciências para o campo estamos falando?}

O grito de "Ocupemos o latifúndio do saber" ecoado pelos coletivos sociais formados por indígenas, negros, quilombolas, ribeirinhos, povos do campo etc. nos espaços acadêmicos manifestando sua chegada e sua presença nas universidades, causa incômodos porque esses sujeitos, ao chegarem, questionam as pedagogias que os excluíram como sujeitos de direito aos conhecimento circulantes na academia (ARROYO, 2014). Nesse sentido, pensar na Educação do Campo "significa pensar sob outra lógica, quer seja a lógica da Terra, a lógica do Campo e, sobretudo, a dos sujeitos que ali vivem, constroem e defendem seu modus vivendi" (ANTUNES-ROCHA; MARTINS, 2011, p. 17 - grifo das autoras).

Ao pensar na formação de professores para o campo é preciso antes e/ou conjuntamente pensar e se questionar sobre o contexto em que esses professores irão trabalhar, as escolas do campo. Afinal, a escola do campo demandada pelos sujeitos e movimentos sociais do campo não se encontra apartada da vida, pelo contrário, se articula com os projetos sociais e 
econômicos do campesinato, cria vínculos e conexões diretas entre a formação recebida e os modos de produção da vida no campo, aliando os processos de ensino-aprendizagem ao universo cultural do campo, enfim, uma escola que possa ser usada como ferramenta na luta pela conquista de seus direitos de cidadãos (ANTUNES-ROCHA, 2009). Dessa forma, pensar a formação de educadores do campo exige o olhar atento para a articulação entre formação docente - escola do campo - sujeitos em formação.

Os sujeitos em formação na Educação do Campo, neste caso licenciandos, não se apresentam passivos, dispostos a ocupar o velho lugar do depositário de conhecimentos construídos por outros modos de pensar e explicar o mundo que lhes foram/são alheios e que lhes ignoraram como sujeitos de conhecimento. Longe disso, são sujeitos que se posicionam, que trazem consigo para a sala de aula o conhecimento de vida forjado na luta (LIMA, 2010). Por isso, discutir a formação de professores para o campo requer uma reflexão sobre a complexidade dos sujeitos que estão sendo formados. A cultura torna-se um componente importante na formação do professor do campo, sendo necessário então, pensar numa formação docente que dialogue com as culturas que serão postas em jogo. E quando pensamos especificamente na formação do professor de ciências para o campo, isso implica trabalhar em diálogo com as tradições, crenças, conhecimentos. Lima (2010) aponta como desafio a construção de uma formação de ciências que seja capaz de aumentar a comunicabilidade entre perspectivas distintas, mas sem desconsiderar que as desigualdades sociais e de falta de acesso à educação podem produzir tensões no ensinar e aprender ciências que se manifestam inclusive na forma de silenciamentos.

É preciso pensar e praticar uma educação em ciências que supere a ideia iluminista de produção de um conhecimento que se diz isento, neutro e distanciado do mundo político e social e colocar em prática uma educação em ciências fruto de uma construção intencionada, endereçada, em que seus constructos não estão deslocados ou fora da lutas dos sujeitos de aprendizagem (RIBEIRO, PARAÍSO, 2012). Falamos portanto, de uma educação científica que reconhece sua posição hegemônica frente à outros modos de conhecimento e antes de se valer do status de ciência ocidental para impor seu discurso de poder e sua racionalidade aos estudantes, que não partilham do mesmo sistema de símbolos e significados, busca trabalhar o ensino de ciências sem desrespeitar as tradições, crenças, valores que fazem parte da identidade de grupos inseridos em culturas que se organizam de modo divergente ao modo da ciência ocidental ${ }^{4}$.

É preciso de um lado relativizar a ciência, contudo sem dissolvê-la a ponto de ser tornar um relativismo estéril, ao mesmo tempo em que se busque reconhecer e valorizar o conhecimento cotidiano sem perseguir seu engessamento (CREPALDE, 2012). Neste sentido, defendemos um ensino de ciências alicerçado na perspectiva intercultural que exige de nós, formadores

[...] a necessidade de sermos antropologicamente relativistas, de modo a nos tornarmos críticos em relação às ciências ocidentais e, portanto, à nossa própria cultura, sem deixarmos de sê-lo, também, em relação à cultura dos nossos alunos. A crítica a essa cultura primeira, todavia, não poderá ocorrer a partir de um olhar etnocêntrico, nem ser dirigida pelo objetivo de diminuirmos a identificação dos estudantes com suas práticas culturais (PAULA, LIMA, 2011, p. 203).

\footnotetext{
${ }^{4}$ Acerca do termo 'Ciência Ocidental', Aikenhead (2009) nos esclarece que a comunidade científica partilha e usufrui de um sistema de significados e de símbolos bem definido, geralmente contam com uma linguagem própria, e possuem suas crenças, valores, convenções, expectativas e tecnologia próprias. Estes atributos ajudam a definir uma cultura que é comumente identificada como 'Ocidental', posto que a cultura da ciência Ocidental surgiu na Europa Ocidental no século XVII e evoluiu dentro dos parâmetros culturais Euro-Americanos como um sistema de símbolos dominado pelo homem branco de classe média e assim "atualmente a cultura da ciência Ocidental existe no seio de inúmeras nações, onde quer que a ciência Ocidental figure (p. 152).
} 
Nesse sentido, a abordagem que nos parece mais coerente com a educação científica que defendemos é a tratada pelo autor canadense Glen Aikenhead, cujos trabalhos se desdobram no esforço de discutir e refletir sobre a interculturalidade no campo da educação em ciências. Este autor discute sobre a educação científica empregada à classes de estudantes ocidentais e também a grupos aborígenes. Para Aikenhead (2009), uma proposta intercultural de ensino de ciências coloca em jogo as visões de mundo culturalmente construídas, ou seja, aprender ciências seria fruto da promoção do encontro cultural do estudante com a ciência ocidental (AIKENHEAD, 2009). É preciso esclarecer que para Aikenhead (2009) o conceito de ciência, aqui falando da ciência ocidental, é apenas uma das formas de saber, explicar o mundo, abordar a realidade e que partilha de "um sistema de significados e de símbolos bem definidos, com o qual interagem socialmente" (p. 95). Nessa perspectiva intercultural, a ciência ocidental é uma das subculturas da cultura ${ }^{5}$ Ocidental, e um ensino intercultural de ciências leva em consideração o reconhecimento da coexistência de diversas culturas ou subculturas num mesmo espaço.

Entendido como empreendimento cultural, o ensino de ciências passa a ser visto como um cruzamento de fronteiras culturais onde o estudante deve transpor desde uma realidade cotidiana baseada em orientações humanistas até o mundo científico da ciência escolar (AIKENHEAD, 2009). Dessa forma, o estudante não chega vazio à sala de aula de ciências, pelo contrário, traz consigo seus pertencimentos sociais, de gênero, geracionais, religioso, étnico dentre outros que são alimentados pelas subculturas à que pertence, isto é, o estudante é um sujeito que partilha múltiplos olhares e vozes sobre o mundo, e dentro do espaço escolar, a ciência será mais uma das subculturas com a qual terá contato.

Uma formação de professores intercultural implica em repensar o papel do educador em formação, além de questionar a que/quem serve uma educação científica. Numa sala de aula de ciências intercultural, o professor teria como objetivo promover, nas aulas de ciências, o reconhecimento das características da subcultura da ciência e facilitar cruzamentos culturais desde o interior até o exterior de tal subcultura (CREPALDE, 2012).

Nossa defesa sobre a educação científica intercultural nos parece adequada quando tomamos tal perspectiva como saída à um ensino de ciências que usa do discurso científico de maneira autoritária, que se apodera da voz dos cientistas como suas autoridades legítimas para se impor, para exercer uma dominação do sujeito em aprendizagem que precisaria abandonar suas crenças, valores e demais sistemas de conhecimento sobre o mundo a fim de "se tornar esclarecido". Ao defender uma formação de professores de ciências para o campo na perspectiva intercultural, buscamos romper com teorias pedagógicas modernas, que inferiorizam os educandos, neste caso povos do campo, colocando-os em uma posição de dominação que transforma o ato de educar em colonização de saberes, poderes e seres (QUIJANO, 2005). Acreditamos que uma educação científica intercultural se faz necessária para superar os modelos pedagógicos excludentes, porque propõe um tratamento igualitário da diversidade, sem sobreposição da cultura dominante sobre outra a ser subordinada, tratando a diferença cultural como fator enriquecedor da prática educacional (PALADINO e ALMEIDA, 2012). Portanto, mais do que valorizar um diálogo entre conhecimentos, a formação de professores na perspectiva intercultural deve ser entendida como uma ruptura com o modelo de conhecimento da modernidade ocidental, que reconhece a pluralidade e diversidade de conhecimentos em detrimento da hierarquização das experiências humanas (ARROYO, 2013, p. 117).

Tomados por esta ótica é que nos propomos a analisar exemplos de cruzamentos de fronteiras que se deram na formação intercultural de professores de ciências para o campo em

\footnotetext{
${ }^{5}$ Neste trabalho empregamos a ideia de cultura que Aikenhead adota, que toma como cultura um conjunto de normas, valores, crenças, expectativas e ações convencionais de um grupo. Quando transposto para os atributos educacionais, esta ideia pode ser associada à educação científica através dos conceitos de conhecimento, capacidades e valores.
} 
que houve movimentos de ressignificação do discurso científico por parte dos sujeitos de aprendizagens.

\section{Nosso jeito de olhar para os dados}

O presente trabalho é recorte de uma pesquisa de mestrado que se desenvolveu com uma turma de 37 licenciandos do campo da UFMG, que cursavam a habilitação em Ciências da Vida e da Natureza. Os dados utilizados para análise foram construídos durante o desenvolvimento do Tempo Escola, quando os alunos em questão cursavam o sexto período do curso.

O principal material de análise da dissertação, ou nosso corpus de dados original, é composto por um conjunto de 23 atividades produções textuais ${ }^{6}$ individuais, que foram realizadas em sala de aula pelos licenciandos, no contexto da disciplina 'A História da vida na Terra' que abordou questões sobre a origem da vida e biodiversidade no planeta, assim como as teorias evolucionistas.

Sobre a condição de produção destas atividades, esclarecemos que logo no início da disciplina, na primeira aula, após fazer uma breve apresentação, a professora pediu que os educandos analisassem uma figura representativa de diversos seres vivos. O objetivo era suscitar nos alunos a discussão sobre as possíveis explicações para a diversidade de vida encontrada no planeta.

Inspirada por uma atividade intercultural proposta por Aikenhead (2009), a professora entregou aos licenciandos uma folha de papel em branco, pediu que eles a dividissem ao meio fazendo um traço e que ali, numa das metades da folha, elaborassem um desenho ou um texto explicativo de como cada um compreendia a diversidade biológica que existe em nosso planeta. Foi solicitado ainda aos estudantes que, ao fazerem essa atividade, tentassem relacionar suas explicações sobre a diversidade biológica a partir das suas histórias/conhecimentos pessoais sobre o assunto. Essas produções ${ }^{7}$ foram retomadas no último dia de aula da disciplina, quando foi solicitado que cada licenciando completasse a atividade e explicasse o que havia mudado e o que não havia mudado nas explicações deles sobre diversidade biológica. Os alunos teriam que comparar o que pensavam antes de estudarem as ideias evolucionistas e o que havia mudado ou não depois do ensino.

Para este artigo optamos por utilizar uma amostra dos dados totais, analisando 4 das 23 atividades. Nossa escolha foi baseada na intenção de trazer à tona apenas os posicionamentos mais representativos dos discursos não colonizados pelo discurso científico. Assim, para este artigo, escolhemos olhar para o segundo texto dos licenciando sem perder de vista a primeira produção textual, de maneira que nossa análise é fruto de um movimento comparativo entre a posição inicial dos alunos e o posicionamento ao fim da disciplina. Acreditamos que comparando-se um texto com o outro podemos avaliar se houve entre eles uma relação de contraposição, de manutenção de pontos de vista ou até mesmo de complementaridade de informações como se fosse uma peça única de discurso.

Para guiar nossas análises elegemos a metodologia qualitativa, especificamente nos apoiamos na Análise Textual Discursiva (ATD) proposta por Moraes e Galiazzi (2007) que parte de um conjunto de textos ou documentos, produzindo assim um metatexto, que descreve e interpreta sentidos e significados, os quais o pesquisador elabora tendo como base o corpus

\footnotetext{
${ }^{6}$ Moraes e Galiazzi (2007) explicam que neste caso o termo "texto" não se refere exclusivamente no sentido das produções escritas, mas que o termo deve ser entendido num sentido mais amplo, que inclui imagens e outras expressões linguísticas, aproximando-se a ideia de textos como discursos.

${ }^{7}$ Por questão de entendimento e organização do nosso trabalho de análise, vamos nomear de Primeiro texto o que foi produzido pelos licenciandos no primeiro dia de aula. E consequentemente, chamaremos de Segundo texto, a segunda parte da atividade que teve sua realização no último dia de aula.
} 
de dados. Nessa metodologia de análise busca-se a compreensão, a reconstrução de conhecimentos existentes em que os novos entendimentos emergem a partir de um processo de intensa impregnação nos materiais da análise, que torna possível a emergência de uma compreensão renovada do todo.

\section{Nosso diálogo com os dados}

Em nossas análises, nos apoiamos nas ideias de Aikenhead (2009) e tomamos como pressuposto o fato de que o ensino de ciências praticado no curso, ou pelo menos na disciplina analisada, segue a perspectiva intercultural. Dessa forma ao falar na aprendizagem de conteúdos por parte dos licenciandos, estamos assumindo como implícito o movimento de cruzamento de fronteiras. Já que na condição de estudantes universitários, supostamente já teriam estudado o assunto em outros contextos escolares ou mesmo participado de discussões fora do espaço escolar. Por esse ângulo, não nos fez sentido apontar se um licenciando cruzou ou não as fronteiras entre as culturas, mas analisar como se deu o processo de apropriação da cultura científica, como os licenciandos lidaram com esse caldo de culturas e se reposicionaram como sujeitos, ou seja, o que pensavam e como passaram a ver.

Por todos esses motivos, voltamos nosso olhar para analisar os dados como tensão entre discursos, olhando para a relação entre discursos colonizados ou não pelo discurso da ciência. Tomamos como base que o colonizado é aquele que se apropria do discurso científico em suas explicações e, em contrapartida, o não-colonizado é aquele que não se convenceu pelo discurso da ciência, que resiste. Isso não quer dizer que o não-colonizado não cruzou a fronteira, pelo contrário, para se posicionar como tal ele precisa fazer o movimento de aproximação com as explicações da ciência, ainda que seja de modo precário, conhecer o discurso alheio, distanciar-se dele, para aí sim se posicionar como sujeito de sentidos. Os não-colonizados se mostram insubmissos à outras culturas (SAHLINS, 1997), mesmo conhecendo a cultura científica, mostrando-se como passíveis de fazer uma integração entre a cultura do cotidiano e a científica, acabam fazendo o movimento inverso, ressignificando seu modo de posicionamento. Posicionamento ressignificado à medida que utiliza da cultura científica para legitimar sua posição de não-colonizado.

Desse modo, fazemos aqui um recorte e trazemos para discussão o posicionamento dos estudantes não-colonizados frente às explicações acerca da diversidade biológica.

\subsection{A apropriação não-colonizada}

No grupo dos estudantes que não se mostraram colonizados pelo discurso da ciência, temos o texto do estudante Pedro ${ }^{8}$ :

Eu tinha uma concepção de que era apenas um fenômeno da natureza, onde a árvore perdia as folhas para produzir melhor. Hoje entendi que é uma adaptação da árvore com o meio e a planta que está acoplada ao umbuzeiro que continua verde porque recebe todos os nutrientes possíveis para a sobrevivência. Pude perceber que todos se adaptam, é o que diz Lamarck.

Pedro, de certo modo, passa a limpo suas ideias iniciais sobre a diversidade biológica e nos aponta que já tinha uma noção acerca do discurso científico quando fala "Eu tinha uma

\footnotetext{
${ }^{8}$ Não esquecendo a questão ética na pesquisa em educação, para que não haja nenhuma circunstância que possa levar os sujeitos pesquisados ao constrangimento, os envolvidos na pesquisa tiveram suas identidades preservadas pelo uso de nomes fictícios.
} 
concepção de que era apenas um fenômeno da natureza...". Apesar de demonstrar estar de acordo com as explicações da ciência na medida em que fala de adaptação, sobrevivência e Lamarck, uma questão nos dá pistas de que internamente o discurso científico sobre o processo evolutivo e a diversidade biológica não está consolidado de forma a colonizar o discurso do licenciando: o uso do discurso indireto ou citações de teóricos.

$\mathrm{O}$ discurso indireto também surge nas explicações de Gabriel que ao ser questionado sobre o que havia mudado e o que não havia mudado nas explicações iniciais deles sobre diversidade biológica, responde que a mudança está no entendimento de que "pela ciência, a vida surgiu na água". Pela forma como a frase ficou solta em resposta à pergunta feita, apostamos que esse posicionamento indica que para o educando a ciência enquanto entidade externa ao seu mundo de significação afirma o surgimento da vida na água, mas ao não se pronunciar como sujeito da frase, ou seja, ao não assumir sua autoria, entendemos que este não seja o posicionamento do educando. Portanto, apesar de entender o discurso científico, mesmo fazendo o cruzamento de fronteiras até o discurso da ciência, seu posicionamento indica a não colonização de seu conhecimento.

Ao utilizarem dessas estratégias linguísticas, os licenciandos parecem querer deixar claro a intenção de demarcar nitidamente a autoria dos discursos, quando são discursos pertencentes a eles e quando se apropriaram do discurso científico circulado em sala de aula para se expressarem. Para nós isso indica a não colonização do discurso pessoal deles pelo discurso científico que continua sendo usado como reprodução e bem demarcado.

Já o estudante Gustavo, constrói o seguinte texto:

Pude perceber que as teorias para o surgimento da vida são muito mais complexas e sugestivas/questionáveis do que a minha concepção prévia, antes eu considerava que a ciência tinha uma única explicação para a origem da vida, após as aulas percebi que este conceito mesmo na ciência pode apresentar contradições e/ou ideias diferenciadas. Mas não podemos deixar de constatar que a diversidade da vida de uma forma ou de outra se dá em consequência dos mais variados ambientes, ou foram criados para viverem naquele determinado ambiente.

Neste caso, entendemos que Gustavo se apropria da forma de construção do discurso científico para se afirmar como não colonizado. Portanto, ele faz apropriação do discurso científico, mas não se deixa colonizar por ele. Prova disso está na comparação do primeiro texto com o segundo. No primeiro não havia menção alguma sobre a perspectiva criacionista, a qual aparece no final do seu segundo texto. Em sua segunda produção o estudante questiona a natureza do conhecimento científico afirmando que este apresenta contradições e pontos frágeis em sua constituição, traz para seu texto a fragilidade das ciências, do campo da disputa das teorias e usa dessas colocações para questionar o próprio conhecimento científico. Dessa forma, Gustavo ressalta em seu discurso as particularidades das ciências e evidencia sua natureza conjectural, trazendo como aspecto negativo a incapacidade deste conhecimento de trazer certeza e satisfação, sentimentos que possivelmente são alcançados pelo estudante ao adotar a sua perspectiva de mundo para as explicações (SEPULVEDA e EL-HANI, 2006).

Passemos à análise do discurso de Fátima:

Nesta primeira teoria religiosa, meus conceitos continuaram iguais. Através da teoria científica aprendi muito e reformulei meus conceitos vendo adaptação, teorias de Darwin, de Lamarck. Percebi evidências das semelhanças nos animais, demonstrando que eles possuem um ancestral comum. 
A resposta dessa licencianda tem um forte argumento de não se deixar colonizar pelo discurso da ciência logo no início do texto. Fátima havia apresentado no primeiro texto duas versões: 1) A de que Deus criou o mundo e tudo que nele existe pelo sopro no molde de barro; 2) A água até os diversos seres vivos com reinos, classe, filo e espécie tiveram origem no Big Bang. É possível observar que a estudante incorpora em seu novo texto a ideia de que a semelhança entre os seres vivos decorre de um ancestral comum. Demonstra que ampliou seu horizonte explicativo quanto às teorias evolucionistas, mas não abandona seu discurso, seu ponto de vista pessoal e religioso ao dizer que "meus conceitos na teoria religiosa continuam iguais". Há duplicidade nas explicações, mas um posicionamento explícito de que a estudante se dá o direito de manter seus conceitos externos ao sistema de domínio da ciência, no âmbito religioso. Claramente, Fátima nos mostra que cruzou as fronteiras culturais, mas que entendeu que no campo da fé, o sistema de explicação da ciência não é suficiente para lhe convencer a colonizar seu discurso pessoal.

Ao testemunhar o surgimento de posicionamentos resistentes ao discurso da ciência, poderíamos encará-los como condição de não-aprendizagem ou mera rebeldia. Entretanto, porque entendemos que a abordagem intercultural colaborou para a promoção da inter-relação entre diferentes culturas, admitimos que tal perspectiva possibilitou aos estudantes a abertura necessária para se posicionarem como não-colonizados.

\section{Lições extraídas}

Nosso contato com a perspectiva intercultural de educação científica a partir da pesquisa realizada e nosso esforço de significação sobre os dados, nos ensinam algumas lições. A primeira delas é que nossa defesa por um ensino de ciências intercultural, antes de ser uma exigência externa e hierarquizada, é condição necessária para a promoção de um ensino sensível e respeitoso com as vivências dos estudantes, um ensino que abre as portas para um franco diálogo entre diversidades de conhecimentos. Essa é uma necessidade demandada pelos coletivos de sujeitos do campo que chegam à universidade e a interrogam sobre seus critérios hegemônicos de validade e de verdade, afirmando seus saberes, contrapondo-os como conhecimentos também, como válidos sob uma outra lógica de criteriar a verdade (ARROYO, 2014).

Assim, a formação de professores de ciências para o campo abre caminho para uma negociação cultural que favorece a integração dialética das diferenças entre os sistemas de conhecimento, que antes de buscar e/ou enfatizar as diferenças para reafirmar a posição assimétrica e hierarquizada entre os campos de conhecimentos, procura formas de no diálogo de saberes intercultural assumir a complementariedade entre as diferentes formas de ver e explicar o mundo.

Reconhecer outros sistemas de construção de conhecimentos como legítimos e válidos para explicar o mundo é uma saída para fugir da assimetria proposta pelo modelo moderno de educação científica, em que o ensino de ciências deve promover o letramento científico no sentido de iluminar, civilizar, tirá-los do lugar de leigos e trazê-los para a posição de especialistas em ciências. Nesse modelo, só há um lugar de fala garantido e validado, o de quem fala em nome da ciência a partir do conhecimento científico enquanto outros tipos de conhecimentos são desprezados ou inferiorizados.

Nesse sentido, o posicionamento dos licenciandos do campo explicitado neste trabalho aponta uma ruptura com a lógica de que esses sujeitos em formação são coletivos incapazes de construir conhecimento. Seus posicionamentos fortemente demarcados pela não colonização de seus discursos são prova de que esses sujeitos se afirmam mais do que resistentes, colocam em jogo suas existências como sujeitos de aprendizagem ativos, capazes de inter-relacionar o conhecimento forjado em suas experiências de humanidades, em seus territórios, povoados por seus passados, memórias e ancestralidades como culturas válidas, como também produção de 
conhecimento. Assim demarcam seu espaço e reafirmam-se como sujeitos de conhecimentos, de culturas, buscam um letramento científico capaz de abrir espaço para sair do lugar de meros coletivos consumidores a coletivos produtores de saber, letrados num sistema complementar que busca uma relação horizontal e menos assimétrica entre os sistemas de conhecimento.

\section{Referências}

ANTUNES-ROCHA, M. I. Licenciatura em educação do campo: histórico e projeto políticopedagógico. In: ANTUNES-ROCHA, M. I. \& MARTINS, A. A. (Org.). Educação do Campo: desafios para formação de professores. Belo Horizonte, MG: Autêntica Editora, 2009.

ANTUNES-ROCHA, M. I.; MARTINS, A. A. Formar docentes para a Educação do Campo: desafios para os movimentos sociais e para a Universidade. In: ANTUNES-ROCHA, M. I.; MARTINS, A. A. (Org.) Educação do Campo: desafios para a formação de professores. Belo Horizonte: Autêntica, 2011.

ARROYO, M. G. Os coletivos diversos repolitizam a formação. In: Diniz Pereira, J. E.; Leão, G. (Org.). Quando a diversidade interroga a formação docente. Belo Horizonte, MG: Autêntica Editora, 2008.

ARROYO, M. G. Currículo, território em disputa. Petrópolis, RJ: Vozes, 2013.

ARROYO, M. G. Outros sujeitos, outras pedagogias. Petrópolis, RJ: Vozes, 2014.

CREPALDE, R. S. Da energia pensada à energia vivida: um diálogo intercultural com as ciências. 166 f. Dissertação (Mestrado) - Faculdade de Educação, Universidade Federal de Minas Gerais, Belo Horizonte, 2012.

LIMA, M. E. C. C. Uma formação em ciências para educadores do campo e para o campo numa perspectiva dialógica. In: DALBEN, A. I. L. F. et al. (Org.) Convergências e tensões no campo da formação e do trabalho docente: Educação Ambiental, Educação em Ciências, Educação em Espaços não-escolares, Educação Matemática. Belo Horizonte: Autêntica, v. 1, p. 167-183, 2010.

MORAES, Roque; GALIAZZI, Maria do Carmo. Análise Textual Discursiva. Ijuí: UNIJUÍ, 2007.

PALADINO, M.; ALMEIDA, N. P. Entre a diversidade e a desigualdade: uma análise das políticas públicas para a educação escolar indígena no Brasil dos governos Lula. Rio de Janeiro: Contra Capa Livraria; LACED/Museu Nacional/UFRJ, 2012.

PAULA, H. F.; LIMA, M. C. C. E. A leitura de textos didáticos de ciências como confronto de perspectivas. Revista Ensaio, Belo Horizonte, v. 13, n. 03, p. 185-205, set.-dez. 2011.

PIO-VENÂNCIO, J. M. Apropriação da escrita no contexto da formação de professores de ciências na educação do campo. 2011. 106 f., enc. Dissertação (mestrado) - Faculdade de Educação, Universidade Federal de Minas Gerais. 
QUIJANO, A. Colonialidade do poder, eurocentrismo e América Latina. In: LANDER, E. (Org.). A colonialidade do saber: etnocentrismo e ciências sociais - Perspectivas Latinoamericanas. Buenos Aires: Clacso, 2005.

RIBEIRO, V.; PARAÍSO, M. A. A produção acadêmica sobre educação do campo no Brasil: currículos e sujeitos demandados. Revista Educação, Porto Alegre, v. 35, n. 2, p. 169-180, maio/ago. 2012.

SEPULVEDA, C; EL-HANI, C. N. Apropriação do discurso científico por alunos protestantes de biologia: uma análise à luz da teoria da linguagem de Bakhtin. Revista Investigações em Ensino de Ciências, v. 11, p. 29-51, 2006.

\section{Sobre as autoras}

Tânia Halley Oliveira Pinto é graduada em Licenciatura em Ciências Biológicas (2008), tem mestrado (2013) e é doutoranda em Educação e Ciências pela Universidade Federal de Minas Gerais. Atualmente é professora no curso de Licenciatura em Educação do Campo, área do conhecimento: Ciências da Natureza na Universidade Federal do Triângulo Mineiro. Compõe o grupo de pesquisa Integração de Saberes na Formação de Professores de Ciências para o Campo.

E-mail: taniahalley@gmail.com.

Maria Emília Caixeta de Castro Lima é licenciada em Química pela Universidade Federal de Minas Gerais (1985), Mestre em Educação pela Universidade Federal de Minas Gerais (1990) e Doutora em Educação pela Universidade Estadual de Campinas (2003). Atualmente é Professora Associada da Universidade Federal de Minas Gerais. Atua na Licenciatura em química, na Licenciatura do Campo e no Programa de Pós-graduação. Consultora de diversas redes de ensino no campo do currículo de química e ciências, avaliação da aprendizagem e formação continuada de professores.

E-mail: mecaixeta@gmail.com.

Andréa Horta Machado possui graduação em Química Licenciatura e Bacharelado pela Universidade Federal de Minas Gerais (1987- 1988), mestrado e doutorado em Educação Metodologia de Ensino - pela Universidade Estadual de Campinas (1992 e 1999). Atualmente é Professora Titular da UFMG em exercício no Colégio Técnico. Atua na formação de professores de Química e Ciências.

E-mail: ahortamachado@gmail.com. 